\title{
Comparison of Large Aperture Scintillometer and Eddy Covariance Measurements: Can Thermal Infrared Data Be Used to Capture Footprint-Induced Differences?
}

\author{
J. C. B. Hoedjes And A. Chehbouni \\ Centre d'Etudes Spatiales de la Biosphère, Toulouse, France \\ J. EZZAHAR \\ Physics Department LMFE, Faculty of Sciences Semlalia, Marrakech, Morocco \\ R. ESCADAFAL \\ Centre d'Etudes Spatiales de la Biosphère, Toulouse, France \\ H. A. R. De Bruin \\ Meteorology and Air Quality Group, Wageningen University, Wageningen, Netherlands
}

(Manuscript received 19 December 2005, in final form 5 July 2006)

\begin{abstract}
Eddy covariance (EC) and large aperture scintillometer (LAS) measurements were collected over an irrigated olive orchard near Marrakech, Morocco. The tall, sparse vegetation in the experimental site was relatively homogeneous, but during irrigation events spatial variability in soil humidity was large. This heterogeneity caused large differences between the source area characteristics of the EC system and the LAS, resulting in a large scatter when comparing sensible heat fluxes obtained from LAS and EC. Radiative surface temperatures were retrieved from thermal infrared satellite images from the Landsat Enhanced Thematical Mapper+ and Advanced Spaceborne Thermal Emission and Reflection Radiometer (ASTER) satellites. Using these images in combination with an analytical footprint model, footprint-weighted radiative surface temperatures for the footprints of the LAS and the EC system were calculated. Comparisons between the difference in measured sensible heat fluxes and the difference in footprint-weighted radiative surface temperature showed that for differences between the footprint-weighted radiative surface temperatures larger than $\pm 0.5 \mathrm{~K}$, correlations with the difference in measured sensible heat flux were good. It was found that radiative surface temperatures, obtained from thermal infrared satellite imagery, can provide a good indication of the spatial variability of soil humidity, and can be used to identify differences between LAS and EC measurements of sensible heat fluxes resulting from this variability.
\end{abstract}

\section{Introduction}

A good knowledge of surface fluxes of sensible $(H)$ and latent heat $\left(L_{v} E\right)$ is of crucial importance for water management, particularly in (semi) arid regions. In many of these regions, the management of irrigation is based on relatively low tech methods for the estimation of latent heat fluxes, such as lysimeters, in combination

Corresponding author address: J. C. B. Hoedjes, Centre d'Etudes Spatiales de la Biosphère (CESBIO), 18 Avenue Edouard Belin, 31401 Toulouse CEDEX 9, France.

E-mail: joost.hoedjes@cesbio.cnes.fr with simple empirical formulas. These evaporation models are used to calculate a potential evaporation or a reference crop evaporation, which, after applying an empirical crop factor, yield actual evaporation [cf. Food and Agriculture Organization of the United Nations (FAO) method]. However, evaporation estimates calculated using this method need to be treated cautiously, as shown by Wallace (1995). A more realistic approach models the turbulent exchanges of heat and water vapor using a network of resistances to describe the soilplant-atmosphere system.

Large irrigated perimeters generally consist of various fields with different crops at different stages of de-

DOI: $10.1175 / J H M 561.1$

(C) 2007 American Meteorological Society 
velopment. Therefore, any modeling effort for water management purposes in these areas requires a large amount of input data to take into account the variability among fields. The increasing availability of highresolution (both spatial and temporal) satellite imagery allows the use of remotely sensed parameters (e.g., surface temperature, albedo, or leaf area index) as input for surface flux models, thus accounting for heterogeneities within the irrigated area.

To validate, calibrate, and check the performance of any model, ground truth data are required. It is generally agreed that the eddy covariance technique is the most accurate means of measuring surface fluxes, but this method has its shortcomings. The system is expensive, and a well-trained staff is needed for the operation, making it difficult to use in, for example, remote areas. Furthermore, the fluxes obtained from eddy covariance (EC) measurements are only representative for a relatively small area around the EC system. So, areally averaged surface fluxes can only be obtained using a network of systems. Another method to obtain measurements of surface fluxes is the scintillation technique. Using a scintillometer, one can obtain pathaveraged surface fluxes over distances of a few hundreds of meters up to $10 \mathrm{~km}$. It is relatively affordable and easy to maintain. A disadvantage of the method is that, contrary to the eddy covariance technique, which uses direct turbulent measurements, it relies on the semiempirical Monin-Obukhov similarity theory (MOST) for the calculation of surface fluxes. Several authors have tested the large aperture scintillometer (LAS), the type of scintillometer which we will use in this study. The LAS appears to be reliable under dry unstable conditions over homogeneous fields, as shown by De Bruin et al. (1995), McAneney et al. (1995), and Meijninger and De Bruin (2000). Chehbouni et al. $(1999,2000)$ and Meijninger et al. (2002b) have shown that the method also works well over heterogeneous surfaces, while Hoedjes et al. (2002) found very promising results over a homogeneous irrigated wheat field affected by regional advection. Hartogensis et al. (2003) have demonstrated the possibility of determining an effective height for scintillometers, enabling its operational use over a slant path or over nonflat terrain. It also enables us to correct for the curvature of the earth, which becomes an issue when measuring over longer transects. Other types of scintillometers include radio wave scintillometers, from which $L_{v} E$ can be obtained (see, e.g., Green et al. 2001 or Meijninger et al. 2002a), or the displaced-beam laser scintillometer (DBLS), which allows direct determination of $u_{*}$, the friction velocity. The DBLS has recently been tested by De Bruin et al. (2002) and Hartogensis et al. (2002). The pathlength is however limited to about $150 \mathrm{~m}$, so it cannot be applied over large irrigated parameters. Note that Vogt et al. (2004) have used a DBLS within an olive tree orchard.

Since the large aperture scintillometer pathlengths are comparable to the resolution of satellite images, LAS measurements enable the validation of remote sensing models. Recently, several studies have been carried out in which ground-based scintillometer data have been used for the validation of remote sensing algorithms (Lagouarde et al. 2002; Meijninger 2003; Watts et al. 2000). A similar approach can be used in a slightly different manner. Since source areas (the area from which the measured flux emanates) of the eddy covariance technique and the scintillometer differ significantly, a direct comparison between the two methods is only possible when the experimental site is homogeneous, a condition which, in practice, is rarely met. So, in most cases, the only useful comparison between the eddy covariance and the scintillation technique can be done when one accounts for the heterogeneity within the footprints (the contribution, per unit flux, of each part of the source area to the measured flux) and differences between the footprints. This can either be achieved by installing EC systems on all surface types within the LAS source area (see, e.g., Meijninger et al. 2002b), or by using remotely sensed data to account for the different characteristics of the footprints.

In the present study, an LAS and an eddy covariance system have been installed over irrigated olive trees, that is, over tall, sparse vegetation. De Bruin et al. (1995) successfully applied the LAS technique over sparse vine grapes, where parameters such as roughness length and zero displacement height were varying in time. Gryning et al. (2001) found a shading effect over a sparse coniferous high-latitude forest, where, depending on the solar angle, the underlying surface is shaded more or less from incoming solar radiation by the canopy, causing different contributions from the soil and canopy to the measured flux. It is expected that, due to the nature of the orchard, a similar effect will be seen.

In this study, an effort is made to quantify differences between sensible heat fluxes, obtained from an LAS and an EC system, caused by differences between the characteristics of the respective footprints. The approach is based on the use of the radiative surface temperature, obtained from thermal infrared satellite data, as indicator of the spatial variability of soil humidity. First, a model for the estimation of sensible heat fluxes from radiative surface temperatures is tested against the EC measurements, using in situ measured radiative 
surface temperatures. This model is then used with the footprint-weighted radiative surface temperatures to check whether a part of the difference between the measured sensible heat fluxes at the time of satellite overpass can be quantified in terms of the difference between the modeled sensible heat flux. When it is assumed that the evolution of the heterogeneities within the experimental site is small during the day, the spatial variability of satellite-derived radiative surface temperatures can be used as indicator of the spatial variability of soil humidity during the hours after the time of satellite overpass. Therefore, footprints are calculated for several 30-min intervals following the time of acquisition of the satellite image. Using the image acquired on a given day, footprint-weighted radiative surface temperatures are calculated for these intervals during that day. The differences between these radiative surface temperatures of the LAS and EC footprints are then compared directly to the differences in measured sensible heat flux for the corresponding intervals, in order to further investigate the role of spatial heterogeneity on differences between sensible heat fluxes measured by EC and LAS.

Compared to earlier studies, in this study the environmental and site conditions differ in the following aspects:

1) The nature of the olive yard (relatively tall and sparse, irrigated trees in a semiarid environment) means transfer processes are more complicated than over short crops.

2) Due to the flood irrigation, the site changes from being almost homogeneous (before irrigation) to very heterogeneous (during irrigation) and back to almost homogeneous (after irrigation).

\section{Surface flux measurements}

\section{a. Flux measurements}

In general, the EC technique is assumed to be the most accurate method for the estimation of turbulent fluxes. Fluxes are calculated as the covariance between fluctuations of vertical wind speed and fluctuations of a scalar (see, e.g., Stull 1988; Moncrieff et al. 1997; Van Dijk et al. 2004). However, as a result of limitations in, for example, sensor design, finite flux averaging, or processing methods, turbulent fluxes measured using the eddy covariance technique have a tendency to underestimate the true atmospheric fluxes (Massman and Clement 2004). Several authors have proposed correction algorithms in order to correct for this underestimation (Schotanus et al. 1983; Moore 1986; Horst 1999; Wilczak et al. 2001; Van Dijk et al. 2003). The resulting
EC-measured turbulent flux consists of the covariant term and the various correction terms. The correction terms used in this study are given in section $3 \mathrm{~b}$.

Another method for the estimation of turbulent fluxes is the scintillation method (see, e.g., Green et al. 1994; De Bruin et al. 1995; Hill 1997; Chehbouni et al. 2000). The large aperture scintillometer consists of a transmitter and a receiver. The transmitter emits electromagnetic radiation over a separation distance (or pathlength), which, depending on aperture size, effective height above the surface, and atmospheric stability, can range from several hundreds of meters up to $10 \mathrm{~km}$. The emitted electromagnetic radiation is scattered by the turbulent atmosphere and the intensity fluctuations measured at the receiver can be related to the pathaveraged structure parameter of the refractive index of air, $C_{n}^{2}$ (Wang et al. 1978). The obtained $C_{n}^{2}$ is path averaged according to a bell-shaped weighting function. Wesely (1976), and more recently Moene (2003), have shown that for scintillometers operating at visible or near-infrared wavelengths, $C_{n}^{2}$ is related to $C_{T}^{2}$, the structure parameter of temperature, by

$$
C_{n}^{2} \approx \frac{A_{T}^{2}}{\overline{T^{2}}} C_{T}^{2}\left(1+\frac{A_{q}}{\bar{q}} \frac{\bar{T}}{A_{T}} \frac{c_{p}}{L_{v}} \beta^{-1}\right)^{2}
$$

Here $T$ and $q$ are temperature and humidity respectively, $c_{p}$ is the specific heat at constant pressure, $L_{v}$ is the latent heat of evaporation, and $\beta$ is the Bowen ratio; $A_{T}$ and $A_{q}$ are coefficients depending on pressure, temperature, humidity, and the optical wavelength at which the scintillometer operates $\left[A_{T}=-0.78(p / T) 10^{-6}\right.$ and $\left.A_{q}=-57.22 q 10^{-6}\right]$. Moene (2003) showed that for standard atmospheric conditions and visible or nearinfrared wavelengths, the factor in front of $\beta^{-1}$ is equal to 0.031 .

Using MOST, $H_{\text {LAS }}$ can be obtained iteratively from $C_{T}^{2}$ and additional wind speed data through the following dimensionless relationship:

$$
\begin{aligned}
\frac{C_{T}^{2}\left(z_{\mathrm{LAS}}-d\right)^{2 / 3}}{T_{*}^{2}} & =f_{T}\left(\frac{z_{\mathrm{LAS}}-d}{L}\right) \\
& =c_{T 1}\left(1-c_{T 2} \frac{z_{\mathrm{LAS}}-d}{L}\right)^{-2 / 3}
\end{aligned}
$$

with the Obukhov length $L=-\left(\rho c_{p} T_{a} u_{*}^{3} / k g H\right)$, the temperature scale $T_{*}=\left(-H / \rho C_{p} u_{*}\right)$ and the friction velocity, $u_{*}$ : 


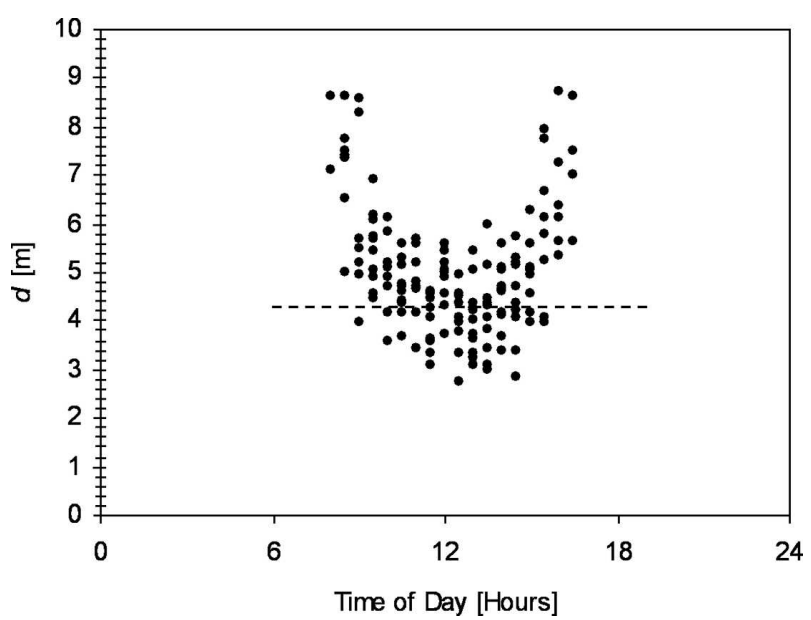

FIG. 1. Diurnal course of the displacement height as obtained from Eq. (4) (dots); horizontal line shows value of the displacement height when calculated as $d=2 / 3 z_{\mathrm{veg}}$.

$$
\begin{aligned}
u_{*}= & \kappa u\left(z_{m}\right)\left[\ln \left(\frac{z_{\mathrm{LAS}}-d}{z_{0 m}}\right)-\psi_{m}\left(\frac{z_{\mathrm{LAS}}-d}{L}\right)\right. \\
& \left.+\psi_{m}\left(\frac{z_{0 m}}{L}\right)\right]
\end{aligned}
$$

Here, $z_{\text {LAS }}$ is the effective height of the LAS above the surface, $z_{0 \mathrm{~m}}$ the roughness length for momentum, $\Psi_{m}$ the stability correction function for the transfer of momentum given by Panofsky and Dutton (1984), $d$ the displacement height, and $\kappa$ the von Kármán constant. During the iteration, $\beta$ is calculated using $H_{\text {LAS }}$, net radiation $\left(R_{n}\right)$, and soil heat flux $(G)[\beta=$ $\left.\left(H_{\mathrm{LAS}} / R_{n}-G-H_{\mathrm{LAS}}\right)\right]$. The empirical constants $c_{T 1}=$ 4.9 and $c_{T 2}=9$ as found by De Bruin et al. (1993) have been used. The physical principles are discussed further in De Bruin et al. (1995), McAneney et al. (1995), or Lagouarde et al. (2002).

In a forthcoming paper, O. K. Hartogensis (2006, personal communication) will discuss the diurnal variation of the displacement height on clear days. The displacement can be considered as the effective height of the surface heat source. This implies that for tall canopies, such as trees, since incoming solar radiation penetrates deeper into the canopy at high solar angles than at lower solar angles, the source of the sensible heat fluxes is located deeper into the canopy at high solar angles than at lower solar angles. This diurnal behavior of $d$ is shown in Fig. 1. Besides the solar angle, this effect depends on site-specific parameters (e.g., tree height and distance between the trees). When $d$ is calculated as a fraction of the vegetation height, that is, when not taking into account this diurnal course, sensible heat fluxes obtained from LAS measurements show a systematic overestimation for low sensible heat fluxes, and an underestimation for high sensible heat fluxes. To get reliable estimates for $d$, Eq. (2) is rewritten to obtain

$d=z_{\mathrm{EC}}-\frac{L_{\mathrm{EC}}}{2 c_{T 2}}\left\{1-\left[1-\frac{4 c_{T 1}^{3 / 2} c_{T 2}}{L_{\mathrm{EC}}}\left(\frac{\theta_{*_{\mathrm{EC}}}^{2}}{C_{T_{\mathrm{EC}}}^{2}}\right)^{3 / 2}\right]^{1 / 2}\right\}$,

where subscript EC denotes variables obtained from the eddy covariance system. O. K. Hartogensis (2006, personal communication) will show a parameterization for $d$, allowing the determination of $d$ for tall vegetation without the use of EC measurements.

\section{b. Footprint model}

The surface fluxes obtained from the flux measurements are influenced by a portion of the surface upstream, called the source area. In other words, the measured flux is the integral of the contributions from the entire source area. To obtain the contribution, per unit flux, of each part of the source area to the measured flux, use is made of a footprint model. Since the early 1990s, many different types of footprint models have been suggested, ranging from simple analytical models (e.g., Schuepp et al. 1990) to more complex Lagrangian models (e.g., Baldocchi 1997; Rannik et al. 2000) or large eddy simulations (LES; e.g., Leclerc et al. 1997). In this study we will use the analytical solution of the advection-diffusion equation as found by Horst and Weil (1992, 1994).

According to Horst and Weil (1992), the footprint function $f$ relates the flux measured at $z_{m}, F\left(x, y, z_{m}\right)$ to the spatial distribution of surface fluxes, $F(x, y, z=$ $0) \equiv F_{0}(x, y)$, that is,

$$
F\left(x, y, z_{m}\right)=\int_{-\infty}^{\infty} \int_{\infty}^{x} F_{0}\left(x^{\prime}, y^{\prime}\right) f\left(x-x^{\prime}, y-y^{\prime}, z_{m}\right) d x^{\prime} d y^{\prime},
$$

where $x$ and $y$ respectively are the upwind and crosswind distances $(\mathrm{m})$ from the point where the measurements are taken. The source-weighted flux is obtained by integration of the footprint function [Eq. (5)]. The footprint function $\bar{f}^{y}$ is calculated using the model of Horst and Weil (1994):

$$
\bar{f}^{y}\left(x, z_{m}\right) \cong \frac{d \bar{z}}{d x} \frac{z_{m}}{\bar{z}^{2}} \frac{\bar{u}\left(z_{m}\right)}{\bar{u}(c \bar{z})} A \exp \left[-\left(\frac{z_{m}}{b \bar{z}}\right)^{r}\right],
$$

where $\bar{z}$ is the mean plume height for diffusion from a surface source $(\mathrm{m}), z_{m}$ is the measurement height, and $\bar{u}(z)$ is the mean wind speed profile. Variables $A, b$, and 
$c$ are functions of the gamma function of shape parameter $r$. Horst and Weil (1992) found the following relationship for the diffusion in the lateral direction (which is commonly assumed to be Gaussian):

$$
D_{y}(x, y)=\frac{1}{\sigma_{y} \sqrt{2 \pi}} \exp \left[-\frac{1}{2}\left(\frac{y}{\sigma_{y}}\right)^{2}\right] .
$$

Here $\sigma_{y}$ is the standard deviation of the lateral spread, which is related to the plume travel time $x / U$ (where $U$ is the plume advection speed) and the standard deviation of the lateral wind fluctuations, $\sigma_{v}$ :

$$
\sigma_{y}=\sigma_{v} \frac{x}{U} .
$$

By combining Eqs. (6) and (7), the three-dimensional footprint function for scalar fluxes is obtained:

$$
F p\left(x, y, z_{m}\right)=\bar{f}^{y}\left(x, z_{m}\right) D_{y}(x, y) .
$$

Equation (9) gives the relative contributions of the sources of a scalar flux in the source area to the measured scalar flux at the measurement height. To obtain the three-dimensional footprint function for the LAS, Eq. (9) is combined with the spatial weighting function (see Wang et al. 1978) of the scintillometer. The model is run at an $x, y$ resolution of $5 \mathrm{~m}$ for the calculation of the EC footprint, and $10 \mathrm{~m}$ for the calculation of the LAS footprint. The output of the footprint model is georeferenced using the Lambert coordinates of the EC system and the LAS, enabling the combination with thermal infrared satellite images.

The Horst and Weil $(1992,1994)$ model was chosen for its relative ease of use, particularly in terms of computational expense compared to the more complex models. Lagrangian and LES-based footprint models are likely to provide a more realistic simulation of footprints over tall vegetation, and, contrary to analytical models, they do have the possibility to cope with inhomogeneous turbulence. However, using data obtained during a tracer experiment, Finn et al. (1996) found very similar results from a Lagrangian stochastic model and the Horst and Weil $(1992,1994)$ model. This indicates that, despite the lack of complexity, the Horst and Weil $(1992,1994)$ model can be used to provide reliable flux footprint predictions.

It should be noted that the spatial weighting function of the LAS, used to determine the footprint of the sensible heat flux measured by the LAS, describes in fact the weighting of $C_{n}^{2}$ along the pathlength over which the LAS measures. Because of the nonlinearity between $C_{n}^{2}$ and $H_{\text {LAS }}$, an error is made when using this weighting function directly for the calculation of the three-dimensional footprint function for $H_{\text {LAs. }}$. However, compared to the uncertainties in the footprint model, this error is believed to be relatively minor.

\section{Experiment}

\section{a. Site description}

In September 2002, within the framework of the SUDMED and IRRIMED projects (see http://www. irrimed.org/), an experiment was set up in the Agdal olive yard near the city of Marrakech, Morocco. The orchard lies in the Tensift Basin, which stretches from the High Atlas Mountains in the east to the Atlantic coast in the west. Olives are one of the main crops in the region, besides oranges and various agricultural crops (mostly cereals). The underlying soil in the region is sandy clay. Most of the crops are irrigated, as the climate in the region is semiarid, with average yearly precipitation in the order of $250 \mathrm{~mm}$. Approximately $75 \%$ of the precipitation falls during winter and spring (November-April). The site is located some $130 \mathrm{~km}$ from the coast and $50 \mathrm{~km}$ from the mountains. A landsea circulation was observed, with northeasterly winds during early morning turning through north in the morning toward northwesterly winds during the afternoon.

The Agdal olive yard (Fig. 2) is bordered on the north and east by the outskirts of Marrakech, and to the south and west by an orange yard, beyond which lies bare land. The total area of the olive yard, which is divided in two by a road, is approximately $275 \mathrm{ha}$. The average height of the olive trees is $6.5 \mathrm{~m}$; the average crown diameter is $6.5 \mathrm{~m}$. Roughness length $z_{0 \mathrm{~m}}$, obtained from eddy covariance measurements, is $0.55 \mathrm{~m}$. The density of the olive trees at our site is $\sim 225 \mathrm{ha}^{-1}$. Most of the trees are around $200 \mathrm{yr}$ old, and even though in some places young trees have been replanted where old trees have died, the olive yard can be considered homogeneous in terms of roughness and land cover. Understory vegetation consists mainly of short weeds, with ground cover ranging from almost no cover $(10 \%-20 \%)$ to almost complete cover $(70 \%-80 \%)$. The olive trees are irrigated through level basin flood irrigation. For this purpose, each tree is surrounded by a small earthen levy, and water is directed to each tree through a network of ditches. A complete irrigation event takes approximately 12 days for the southern part and around 15 days for the slightly larger northern part, as it is done by flooding small plots one after the other. From the start of the experiment in October 2002, until October 2003, 11 irrigation events took place. Averaged over the orchard, $80 \mathrm{~mm}$ of water was given during 

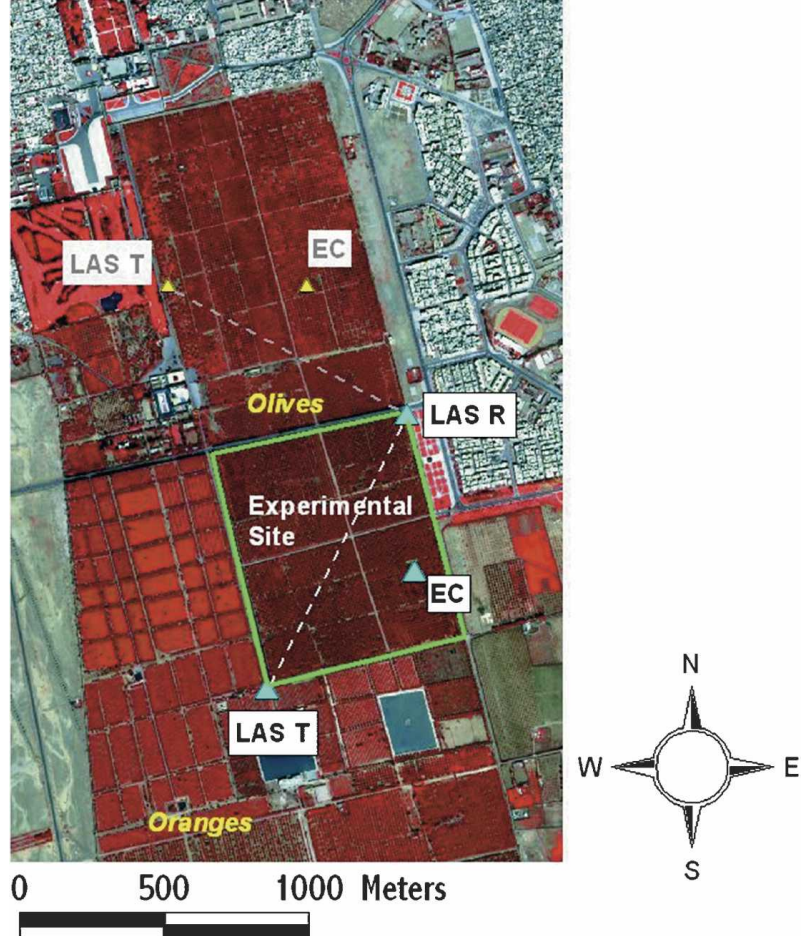

FIG. 2. Quickbird image of the experimental area (outlined in green). Locations of LAS ( $\mathrm{T}$ and $\mathrm{R}$ stand for transmitter and receiver, respectively) and EC system are shown. Northeast of the experimental area lies the outskirts of Marrakech; southwest lies an orange orchard, beyond which lies bare soil.

each irrigation. Since the irrigation always starts on the southern border of the orchard, progressing toward the north, the irrigation takes place in a direction opposite to the main wind direction. Therefore, during irrigation events, field-scale wet advection is unlikely to be observed in the scintillometer measurements.

During the first months of the experiment, from day of year (DOY) 272 until DOY 332 (2002), measurements were carried out in both the southern and the northern part. Thereafter the measurements in the northern part ended, and in the southern part they continued until September 2004 (DOY 271); the resulting dataset covers two years.

\section{b. Flux and micrometeorological measurements}

In September 2002, measurements were set up in both the northern and the southern part of the Agdal orchard. Both sites were similarly instrumented; in this study we will focus on the measurements in the southern part (in Fig. 2 the position of the EC system, meteorological station, and the LAS transect for both the northern and southern site are depicted).

In the southeastern part of the southern site, a 9.2- $\mathrm{m}$-tall tower was installed for the eddy covariance and micrometeorological measurements. During the first three months of the experiment, the EC system, installed at $8.8 \mathrm{~m}$, consisted of a 3D sonic anemometer (CSAT3, Campbell Scientific Ltd.) and an open-path infrared gas analyzer (CS7500, Campbell Scientific Ltd.). Data were collected using a CR23X datalogger (Campbell Scientific Ltd.) and an on-site portable computer to enable the storage of large raw data files. After the first three months of the experiment, the CS7500 Infrared Gas Analyzer (IRGA) was replaced with a Krypton hygrometer (KH20, Campbell Scientific Ltd.), and the datalogging system was replaced with a CR5000 datalogger (Campbell Scientific Ltd.), equipped with a 1 Gb Personal Computer Memory Card International Association (PCMCIA) card for the storage of large raw data files. Fluxes were later calculated offline, using the eddy covariance processing software "ECpack," developed by the Meteorology and Air Quality Group, Wageningen University. The software performs the following corrections:

- data are corrected for the distortion of turbulent flow by relatively small obstacles (e.g., the sonic anemometer);

- the input data are corrected for known delays between the sonic anemometer and the optical hygrometer;

- planar fit coordinate rotation (Wilczak et al. 2001);

- correction of the optical hygrometer measurements for drift, using slow measurements from a wet-bulb system;

- linear detrending of variances and covariances;

- the sonic temperature is corrected for humidity effects (Schotanus et al. 1983);

- in the case of the Krypton hygrometer, which is sensitive to oxygen, an oxygen correction is carried out (Van Dijk et al. 2003);

- corrections are carried out to correct for all types of frequency response errors (e.g., limited frequency response of sensors and dataloggers, sensor separation, or pathlength integration) (Moore 1986; Horst 1999);

- the Webb velocity is included in the mean vertical velocity (Webb et al. 1980).

All corrections, except for the first two, are determined iteratively; the magnitudes of these corrections depend on the atmospheric conditions. More details on the procedures and the processing software can be found in Van Dijk et al. (2004). The software is available for download at http://www.met.wau.nl/.

A $0.15-\mathrm{m}$ aperture scintillometer (LAS, manufactured by the Meteorology and Air Quality Group, Wageningen University) with a $\lambda_{\text {LAS }}=0.94 \mu \mathrm{m}$ LED 
source was set up diagonally over the field, with the receiver at the northeast corner and the transmitter at the southwest corner of the field, providing a good fetch for prevailing wind directions. The pathlength between transmitter and receiver was $1070 \mathrm{~m}$, and the height of the transect above the surface was $13 \mathrm{~m}$. Data from the LAS were measured at a frequency of $1 \mathrm{~Hz}$ and stored as 1-min averages using a CR510 datalogger (Campbell Scientific Ltd.).

Besides the flux measurements, a large array of micrometeorological and hydrological measurements has been carried out. Wind speed and direction was measured using a Young WP200 wind vane/anemometer (R.M. Young Company); air temperature and relative humidity were measured at two levels using HMP45C temperature and relative humidity probes (Vaisala). Net radiation above the vegetation was measured using a CNR1 radiometer (Kipp \& Zonen) and a Q7 (REBS) at a height of $8.4 \mathrm{~m}$; soil net radiation was measured using a Q6 (REBS) at a height of $1 \mathrm{~m}$. Radiative soil and vegetation temperatures were measured using two IRTS-Ps (Apogee), with a 3:1 field of view, at heights of 1 and $8.4 \mathrm{~m}$ respectively. Soil heat flux was measured using soil heat flux plates (Hukseflux) at three locations in order to get good average values; underneath the canopy (always shaded), in between the trees (mostly sunlit), and on an intermediate position. Soil temperature was also measured at various locations at depths of $5,10,20,30$, and $50 \mathrm{~cm}$, using TP107 thermistor probes (Campbell Scientific Ltd.). Water content reflectometers (CS616, Campbell Scientific Ltd.) were installed at depths of 5, 10, 20,30, and $40 \mathrm{~cm}$ in order to measure the soil humidity profile. Measurements were taken at $1 \mathrm{~Hz}$ and averages stored at 30-min intervals on CR10X dataloggers. Besides these, other measurements include sap flow measurements, isotope sampling (see Williams et al. 2004), and LAI measurements.

\section{c. Thermal infrared satellite imagery}

During the experiment, nine Landsat-7 Enhanced Thematic Mapper+ $($ ETM +$)$ and two Advanced Spaceborne Thermal Emission and Reflection Radiometer (ASTER) images of the experimental area were acquired. The ETM+ images, with a spatial resolution of $30 \mathrm{~m}$ in the visual bands and $60 \mathrm{~m}$ in the thermal infrared bands, were acquired on DOY 311 and 359 (both in 2002) and DOY 26, 42, 58, 90, 106, and 138 (the latter all in 2003). The ASTER images were acquired on DOY 282 and 289 (2003), and have a spatial resolution of $15 \mathrm{~m}$ in the visual bands and $90 \mathrm{~m}$ in the thermal infrared bands. All images were cloud free for the experimental area.

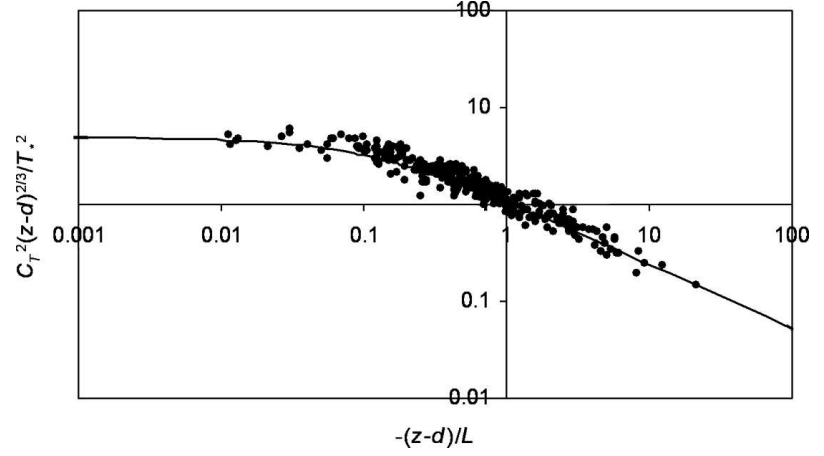

FIG. 3. Observed values of $C_{T}^{2}(z-d)^{2 / 3} / T_{*}$ (with $C_{T}^{2}$ obtained from the LAS) plotted against observed $(z-d) / L$ during conditions with minimal advection. Solid line represents 4.9[1 $(z-d) / L]^{-2 / 3}$.

\section{Comparison sensible heat fluxes-Qualitative approach}

During this study, only sensible heat fluxes will be considered, since these are the only fluxes that are obtained from both LAS and EC system. The sensible heat fluxes from the LAS are obtained by iteration using Eqs. (1)-(3), with values of $T, u, R_{n}$, and $G$ measured at the location of the EC system, and $z_{0 \mathrm{~m}}$ is estimated from EC data. In this study, $d$ is obtained from Eq. (4), using EC measurements. Note that for the calculation of the sensible heat fluxes, the additional data are assumed to be representative for the entire footprint of the LAS. Even though both latent and sensible heat fluxes are measured directly with the eddy covariance technique, many authors reported errors in the closure of the energy balance, sometimes as high as 40\% (e.g., Bernhofer and Vogt 1999; Twine et al. 2000; Hoedjes et al. 2002; Oncley et al. 2002). When comparing latent heat fluxes from the eddy covariance method with latent heat fluxes from the LAS, $L_{v} E_{\mathrm{LAS}}$, which are obtained by energy balance closure $\left(L_{v} E_{\mathrm{LAS}}=R_{n^{-}}\right.$ $G-H_{\text {LAS }}$, with $R_{n}$ net radiation and $G$ the soil heat flux), the nonclosure of the energy balance with the eddy covariance technique introduces an extra error in the comparison. Furthermore, we will only consider unstable conditions $[(z-d) / L<0]$.

To ascertain that $C_{T}^{2}$ from the LAS behaves according to MOST over tall, sparse vegetation, observed values of $C_{T}^{2}(z-d)^{2 / 3} / T_{*}$ have been plotted against observed values of $(z-d) / L$ in Fig. 3, together with the scaling curve as found by De Bruin et al. (1993) [Eq. (2)]. Values of $T_{*}$ and $L$ have been taken from the EC measurements. To minimize the effect of advection, intervals following rain events have been chosen. When testing the applicability of MOST relationships, one should pay attention to possible effects of spurious cor- 
relation (Hicks 1981). De Bruin et al. (1993) stated that when it is found that data fulfill MOST relationships such as Eq. (2), this is an insufficient condition that flux estimates based on these relationships are reliable as well. This is due to the spurious correlation effect. According to De Bruin et al. (1993), to overcome this problem, the final test of any MOST approach is a comparison between fluxes derived from MOST and independently measured fluxes. In the case of the scintillometer method, estimates of sensible heat fluxes are based on observations of $C_{T}^{2}$ and wind speed and the independent values are obtained from eddy covariance measurements. This means that there is no self-correlation. De Bruin et al. (1993) tested Eq. (2) this way; that is, besides a direct test of Eq. (2), a test of the derived sensible heat flux is also presented. The results were very good, so it can be concluded that spurious correlation has only a small effect on fluxes derived from Eq. (2). It is therefore fair to state that in the context of the present study, MOST Eq. (2) is fully applicable. It also implies that values for $d$, obtained from eddy covariance measurements using Eq. (4), can be used. Recently, Hartogensis and De Bruin (2005) discussed spurious correlation effects on similar MOST relationships in the stable boundary layer. Note that Klipp and Mahrt (2004) did not compare fluxes derived from MOST flux-profile relationships with fluxes from eddy covariance, as done by De Bruin et al. (1993). See also Johansson et al. (2001), Andreas and Hicks (2002), and Johansson et al. (2002).

During the days before an irrigation event, the site can be considered homogeneous. Throughout the orchard, the top layer of the soil is very dry. Then, during the irrigation, the method of irrigation causes a large heterogeneity. During the 12 days of each irrigation event, the top layer of the soil in the irrigated part of the orchard is saturated, while the top layer of the soil in the nonirrigated part is very dry. In Fig. 4, an image from the Quickbird satellite of the experimental site is used as background for a rough sketch of the irrigation schedule. Also shown are the footprints of the LAS and the EC system (area corresponding to approximately $95 \%$ of the sensible heat flux) for the prevailing wind direction. The irrigation is not mechanized, and both the exact schedule and the speed of irrigation depend on human factors (e.g., available manpower). Figure 4 shows that for the prevailing wind direction during daytime, the source area of the EC system will be irrigated well before the entire source area of the LAS is irrigated, and large differences in the surface characteristics of the source areas of the two methods will occur. Also, the smaller source area of the EC system is irrigated much faster than the much larger source area of

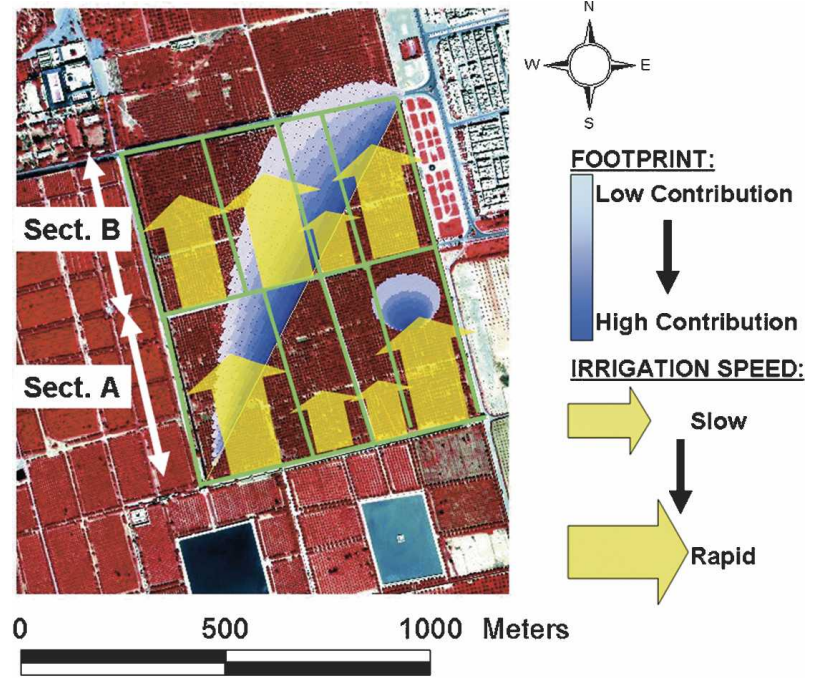

FIG. 4. Overview of irrigation schedule in the southern part of the Agdal olive yard. Irrigation starts in the southern sector A, simultaneously in all four zones (indicated with green lines), but advances with different speed in the different zones. Once sector A is fully irrigated, irrigation starts in sector B. Footprints of the LAS and EC system are shown in blue.

the LAS, and therefore, the irrigation causes a much more abrupt change in the eddy-covariance-measured sensible heat flux than in the sensible heat flux measured by the LAS. After the irrigation, due to the relatively large amount of irrigation water given during each irrigation, the top layer of the soil in the entire orchard is close to saturation, causing conditions to become once more homogeneous.

As an illustration of the influence of an irrigation event on the sensible heat fluxes measured by EC and LAS, comparisons between $H_{\mathrm{EC}}$ and $H_{\mathrm{LAS}}$ (for unstable conditions) before, during, and after a typical irrigation event are shown in Figs. 5a, 5b, and 5c, respectively. Each period covers around 8 days, before, during, and after the irrigation event that took place from DOY 209 until DOY 221. A similar behavior is observed for all irrigation events.

Figure 5a shows a good correlation between $H_{\mathrm{EC}}$ and $H_{\mathrm{LAS}}$, but $H_{\mathrm{LAS}}$ systematically overestimates $H_{\mathrm{EC}}$. This can be explained in large part by the advection of dry, warm air from the area surrounding the orchard. De Bruin et al. (1991) found a similar overestimation of fluxes calculated using MOST after a dry-to-wet transition. As found by Hoedjes et al. (2002), the relative overestimation of $H_{\mathrm{LAS}}$ is largest for low fluxes, during near-neutral unstable conditions. During these conditions, the internal adapted layer [the region of the atmosphere locally adapted to the new surface conditions (irrigated olive trees)] is less well developed than dur- 

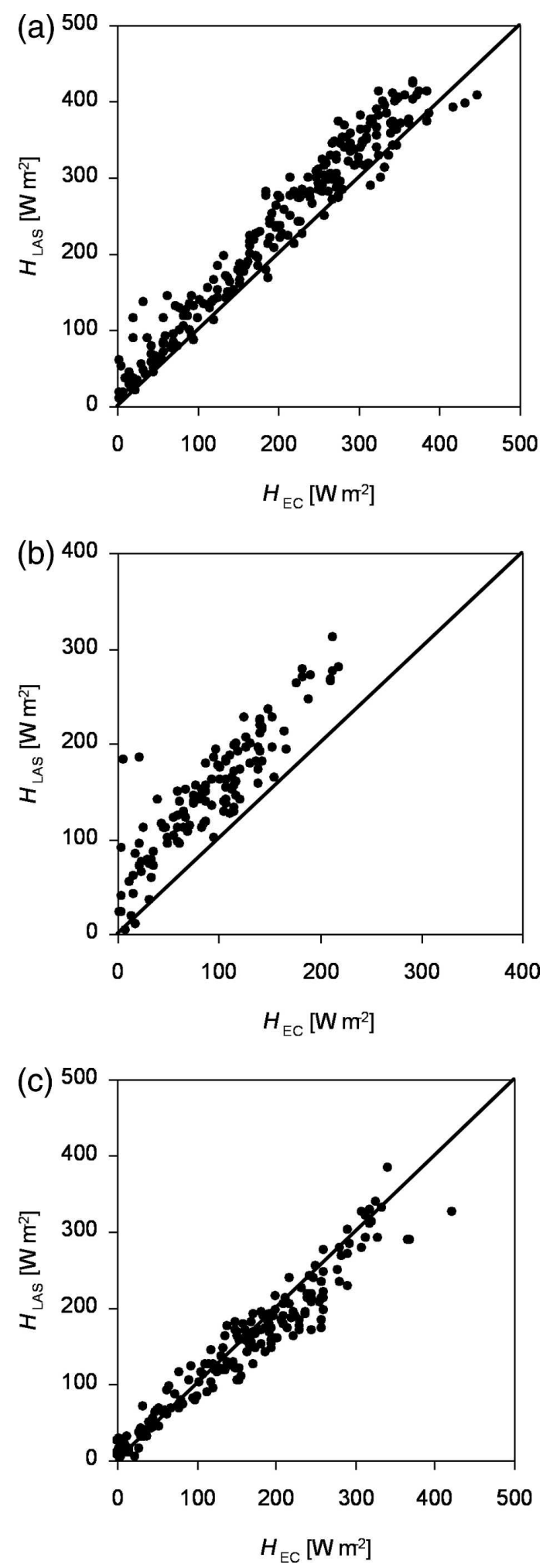

FIG. 5. (a) Comparison of $H_{\mathrm{LAS}}$ and $H_{\mathrm{EC}}$, dry conditions, just before the irrigation event that took place from DOY 209 until DOY 221. (b) Comparison of $H_{\mathrm{LAS}}$ and $H_{\mathrm{EC}}$ during the irrigation event that took place from DOY 209 until DOY 221. (c) Comparison of $H_{\mathrm{LAS}}$ and $H_{\mathrm{EC}}$, wet conditions, just after the irrigation event that took place from DOY 209 until DOY 221. ing very unstable conditions, and the LAS signal is more affected by entrainment of dry air from the area surrounding the orchard into the internal adapted layer. The advection issue has been further investigated by De Bruin et al. (2005). Moene (2003) has pointed out that in the derivation of Eq. (1), temperature and humidity fluctuations are assumed to have a perfect correlation $\left(R_{T q}=1\right)$, and the correlation between temperature and vertical wind speed $(w)$ fluctuations is assumed to be equal to the correlation between humidity and vertical wind speed fluctuations $\left(\left|R_{w T}\right|=\left|R_{w q}\right|\right)$. In this case, $R_{T q}$ is around 0.75 or lower, and $\left|R_{w T}\right|$ and $\left|R_{w q}\right|$ do not behave similarly. This causes an overestimation in $C_{T}^{2}$ values calculated from Eq. (1), resulting (in our case) in an additional slight overestimation of $H_{\text {LAs }}$ (around $4 \%$ ).

In Fig. 5b, the source area of the EC system has largely been irrigated, whereas the larger source area of the LAS is still only partially irrigated. Consequently, the decrease in $H_{\mathrm{EC}}$ is more sudden than the decrease in $H_{\text {LAS }}$, causing a large disagreement between $H_{\text {LAS }}$ and $H_{\mathrm{EC}}$ during an irrigation event.

Finally, in Fig. 5c, both source areas have been fully irrigated. Since irrigation in the source area of the EC system takes place well before the irrigation of the entire source area of the LAS, after the irrigation event the average surface soil humidity in the EC footprint will be lower due to infiltration and soil evaporation than the average surface soil humidity in the LAS footprint. This results in higher values of $H_{\mathrm{EC}}$ than $H_{\mathrm{LAs}}$. For low fluxes, $H_{\mathrm{LAS}}$ overestimates $H_{\mathrm{EC}}$ slightly due to advection.

Statistical data, as well as the range of the volumetric water content throughout the orchard (at a depth of $0.05 \mathrm{~m}$ ) for these three periods, are shown in Table 1. The range of the volumetric water content shows that before or after an irrigation event, the soil humidity will vary somewhat around the given values throughout the site, but without large deviations. During an irrigation event, the spatial variability of soil humidity within the experimental site is large. Starting at the southern border of the site, irrigation progresses slowly toward the northern border, causing the volumetric water content within the experimental site at a given time to vary between near wilting point (before irrigation) and saturation (after irrigation). Table 1 also shows that disagreements between $H_{\mathrm{EC}}$ and $H_{\mathrm{LAS}}$ are largest during irrigation events, indicating that these disagreements are in large part caused by the differences in characteristics of the footprints of LAS and EC caused by the irrigation. Since soil temperature is related to soil humidity through soil evaporation, information on the 
TABLE 1. Statistics of comparison between $H_{\mathrm{EC}}$ and $H_{\mathrm{LAS}}$ and soil humidity, before, during, and after the irrigation event that took place from DOY 209 until DOY 221.

\begin{tabular}{lcccc}
\hline \hline \multicolumn{1}{c}{ Period } & Linear regression $\left(\mathrm{W} \mathrm{m}^{-2}\right)$ & $R^{2}(-)$ & RMSE $\left(\mathrm{W} \mathrm{m}^{-2}\right)$ & Volumetric water content $\left(\mathrm{m}^{3} \mathrm{~m}^{-3}\right)$ \\
\hline Before irrigation & $H_{\mathrm{LAS}}=1.02 H_{\mathrm{EC}}+28.42$ & 0.95 & 36 & $0.21-0.18$ \\
During irrigation & $H_{\mathrm{LAS}}=1.06 H_{\mathrm{EC}}+49.88$ & 0.80 & 63 & $0.18-0.16$ (before irrigation) \\
& & & $0.15-0.50$ (during irrigation) \\
& & 0.93 & 29 & $0.50-0.30$ (after irrigation) \\
After irrigation & $H_{\mathrm{LAS}}=0.86 H_{\mathrm{EC}}+11.25$ & & $0.30-0.25$ \\
\hline
\end{tabular}

spatial variability in soil humidity can be obtained from thermal infrared satellite images (Merlin et al. 2005).

\section{Comparison sensible heat fluxes-Quantitative approach}

In this section, an effort is made to explain differences between $H_{\mathrm{EC}}$ and $H_{\mathrm{LAS}}$ using thermal infrared satellite imagery. First, a simple model, based on the bulk aerodynamic relationship to estimate sensible heat fluxes, is tested for the experimental site. This model is then used with EC and LAS footprint-weighted radiative surface temperatures to model sensible heat fluxes, representative for the footprints of EC and LAS. Differences between these fluxes are compared to differences between the measured fluxes. To further investigate the role played by the footprint-weighted surface temperatures on the difference between the measured fluxes, footprint-weighted surface temperatures are calculated for several 30-min intervals following the time of acquisition of the satellite image. The difference between these temperatures is compared to the difference between $H_{\mathrm{EC}}$ and $H_{\mathrm{LAS}}$ for each interval.

\section{a. Model description}

In the present study we will use a simple two-layer model, based on the bulk aerodynamic relationship to estimate sensible heat flux $H\left(\mathrm{~W} \mathrm{~m}^{-2}\right)$, as found by Lhomme et al. (1994):

$$
H_{\mathrm{Mod}}=\rho c_{p} \frac{\left(T_{e}-T_{a}\right)}{\left(r_{a}+r_{e}\right)},
$$

where $\rho$ is the air density $\left(\mathrm{kg} \mathrm{m}^{-3}\right), c_{p}$ is the specific heat of air at constant pressure $\left(\mathrm{J} \mathrm{kg}^{-1} \mathrm{~K}^{-1}\right), T_{a}$ is the potential air temperature at reference height $(K)$, and $r_{a}$ is the aerodynamic resistance to heat transfer between the level of apparent sink of momentum and the reference height $\left(\mathrm{s} \mathrm{m}^{-1}\right)$ (Brutsaert 1982). Here $T_{e}$ is the equivalent temperature $(\mathrm{K})$, the weighted mean of the soil $\left(T_{s}\right)$, and foliage $\left(T_{f}\right)$ temperature, defined by

$$
T_{e}=\frac{\left(r_{\mathrm{af}} T_{s}+r_{\mathrm{as}} T_{f}\right)}{\left(r_{\mathrm{as}}+r_{\mathrm{af}}\right)},
$$

and $r_{e}$ is the equivalent resistance $\left(\mathrm{s} \mathrm{m}^{-1}\right)$, given by

$$
r_{e}=\frac{r_{\mathrm{af}} r_{\mathrm{as}}}{\left(r_{\mathrm{af}}+r_{\mathrm{as}}\right)} .
$$

For $r_{\mathrm{as}}$, the aerodynamic resistance between the soil and the canopy source height $\left(\mathrm{s} \mathrm{m}^{-1}\right)$, the formulation found by Shuttleworth and Gurney (1990) is used, and $r_{\mathrm{af}}$ is the bulk boundary layer resistance of the canopy $\left(\mathrm{s} \mathrm{m}^{-1}\right)$ as found by Choudhury and Monteith (1988).

However, Eq. (10) requires an accurate knowledge of $T_{s}$ and $T_{f}$, which are not easily obtainable from remote sensing systems. Lhomme et al. (1994) have shown that $T_{e}$ can be related to $T_{r}$, the radiative surface temperature $(\mathrm{K})$ by

$$
T_{e}-T_{r}=-c\left(T_{s}-T_{f}\right)=-c \delta T,
$$

with $c$ defined by

$$
c=\left[\frac{1}{1+\left(r_{\mathrm{af}} / r_{\mathrm{as}}\right)}\right]-f
$$

and $f$ is the fractional vegetation cover (for the experimental site, $f=0.6$ ). Here $\delta T$ can be approximated by

$$
\delta T=a\left(T_{r}-T_{a}\right)^{m},
$$

with $a$ and $m$ empirical coefficients ( $a$ a positive real number and $m$ a positive integer). Now Eq. (10) can be rewritten into Eq. (16):

$$
H_{\mathrm{Mod}}=\rho c_{p}\left[\frac{\left(T_{r}-T_{a}\right)-c \delta T}{r_{a}-r_{e}}\right] .
$$

By iterating Eq. (16) to obtain values of $r_{a}$ and $r_{e}$, which are functions of $u^{*}$ and $L$, sensible heat fluxes can be calculated as a function of the difference between radiative surface temperature and air temperature.

\section{b. Model calibration}

To test the performance of the bulk aerodynamic method before applying the method to the satellite images, the model is run using in situ-measured values of the radiative surface temperature. However, as pointed out by Bosveld et al. (1999) and others, in crops with a complex geometry (such as olives), it is difficult to ob- 


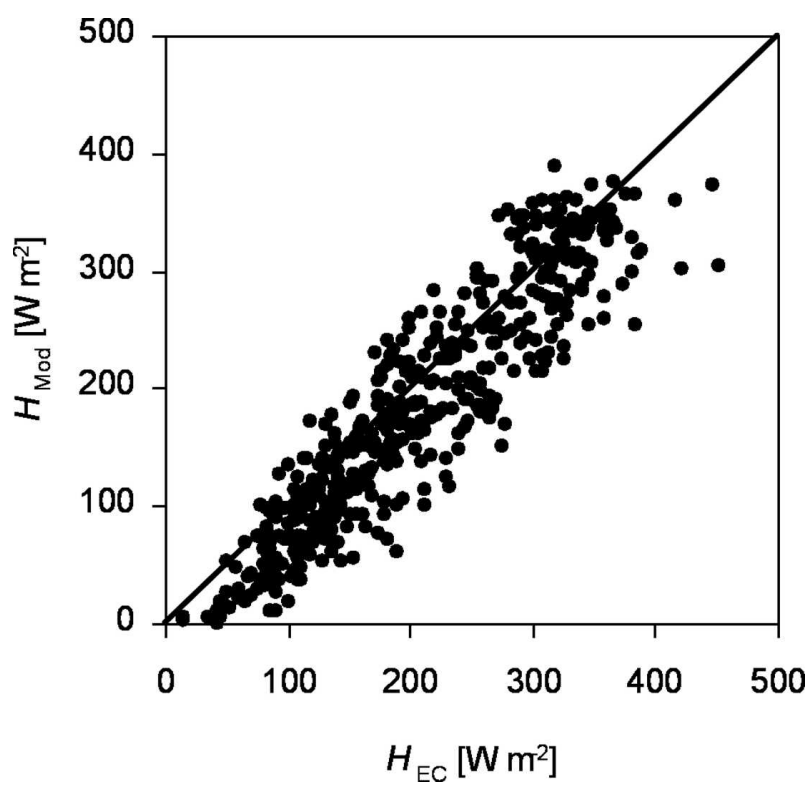

FIG. 6. Comparison between the modeled sensible heat flux, $H_{\text {Mod }}$, using radiometric surface temperature from the CNR1 radiometer, and the sensible heat flux measured by the eddy covariance system, $H_{\mathrm{EC}}$.

tain representative values of the (radiative) component temperatures using infrared thermometers (IRTs), due to for example, shadow effects, or the narrow field of view of the IRTs. In this study, the measurements from the IRTs showed large scatter, and the measurements were not considered to be representative for the temperature of the soil and vegetation surfaces. Therefore we will use the radiative surface temperature obtained from the measurement of longwave incoming and outgoing radiation from the CNR1 radiometer, which has a field of view of approximately $150^{\circ}$. Even though errors arise due to the complexity of the site (e.g., value of surface emissivity, siting of the instrument), as well as due to instrument errors, these measurements are trusted to give a representative value of the radiative surface temperature $T_{r}(\mathrm{~K})$ of the ensemble of soil and canopy.

When no irrigation is taking place, the source area of the EC system can be considered homogeneous, and the assumption can be made that the value of $T_{r}$ is representative of the entire source area of the EC system (typically, $90 \%$ of the flux comes from within $40 \mathrm{~m}$ upwind of the eddy covariance system). Using this radiative surface temperature in Eq. (16), the modeled sensible heat flux, $H_{\mathrm{Mod}}$, is calculated and compared to the sensible heat flux measured by the eddy covariance system, $H_{\mathrm{EC}}$, in order to adjust coefficients $a$ and $m$ in Eq. (15) to optimize correlation and RMSE ( $a=0.05$ and $m=1$ ). In Fig. 6, a comparison between the sen- sible heat flux modeled using Eq. (16), $H_{\mathrm{Mod}}$, and $H_{\mathrm{EC}}$ is shown. This comparison between $H_{\mathrm{Mod}}$ and $H_{\mathrm{EC}}$ yields $H_{\mathrm{Mod}}=1.00 \mathrm{H}_{\mathrm{EC}}-24.09$, with $R^{2}=0.86$ and RMSE $=46 \mathrm{~W} \mathrm{~m}^{-2}$. Volumetric water content for this comparison varies between $0.40 \mathrm{~m}^{3} \mathrm{~m}^{-3}$ and $0.25 \mathrm{~m}^{3}$ $\mathrm{m}^{-3}$. Note that the main objective of this comparison is not a true validation of the model, but to test whether the model is capable of calculating realistic sensible heat flux estimates, using radiative surface temperature, before using it with the satellite-derived radiative surface temperatures.

\section{c. Footprint-induced differences between $H_{E C}$ and $H_{L A S}$ explained by remote sensing}

To correct the thermal infrared satellite images for atmospheric effects, an empirical atmospheric correction has been carried out using ground measurements. For this correction, use is made of the radiative surface temperatures obtained from CNR1 radiometers. During the experiment, a second, similarly instrumented site was operational during the time of acquisition of the satellite images. This site, an irrigated wheat field, is located some $25 \mathrm{~km}$ east of the Agdal olive yard, so it is safe to assume that there are no significant differences in the atmospheric conditions between the two sites. The radiometers at each site have been installed at approximately $3 \mathrm{~m}$ above the vegetation. Since the CNR1 has a field of view of approximately $150^{\circ}$, and considering the surface surrounding the instrument's location to be homogeneous (as long as no irrigation event is taking place within the radiometer's field of view), the obtained radiative surface temperatures are assumed to be representative for the satellite image pixel in which the instrument is located. By comparing these radiative surface temperatures, measured at the two experimental sites, to the satellite-derived radiative surface temperatures for the corresponding pixels, an offset (specific for each satellite image) and an average gain (0.95) were found. This gain and offset is then used to correct each image for atmospheric contributions.

In this study we will only consider the differences between satellite-derived radiative surface temperatures, or the difference between sensible heat fluxes modeled using these temperatures. With coefficient $m$ in Eq. (15) equal to 1, the model proposed by Lhomme et al. (1994) becomes a linear function of the radiative surface temperature. Therefore, errors in the satellitederived radiative surface temperatures due to the method of atmospheric correction (e.g., due to the assumption that the radiative surface temperature measured by the radiometer is representative for the pixel in which the instrument is located) will be cancelled out, and the relatively low accuracy of the atmospheric 


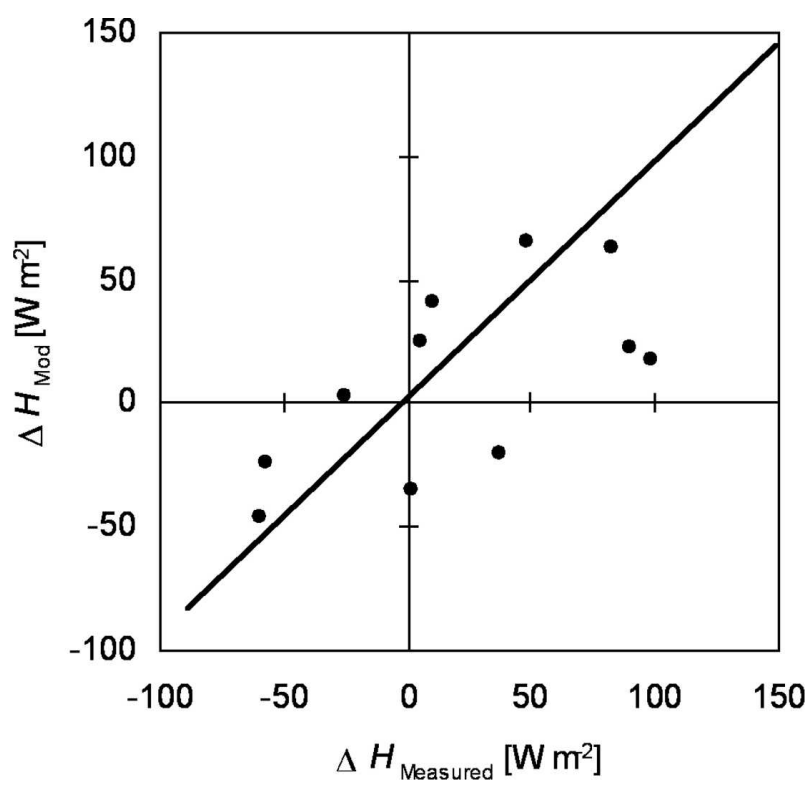

FIG. 7. Comparison of differences between measured $\left(\Delta H_{\text {Measured }}\right.$ $=H_{\mathrm{LAS}}-H_{\mathrm{EC}}, 30$-min interval) and modeled (using satellitederived footprint-weighted radiative surface temperatures within the footprints of EC and LAS, $\Delta H_{\text {Mod }}=H_{\text {ModLAS }}-H_{\text {ModEC }}$ ) sensible heat fluxes at the time of acquisition of the satellite image.

correction has no influence on the results presented in this study.

In Fig. 7, the difference between the sensible heat fluxes modeled using the model described in section $5 \mathrm{a}$ with $\left\langle T_{r, \text { LAS }}\right\rangle$ and $\left\langle T_{r \text {,EC }}\right\rangle$ (the footprint-weighted radiative surface temperature of the LAS and EC footprints, respectively, with angular brackets denoting spatially averaged values), $\Delta H_{\text {Mod }}=\left(H_{\text {ModLAs }}-H_{\text {ModeC }}\right)$, is plotted against the difference between the measured fluxes, $\Delta H_{\text {Measured }}=\left(H_{\text {LAS }}-H_{\mathrm{EC}}\right)$. Measured fluxes are representative for the 30-min interval during which the satellite image was acquired. Correlation $R^{2}=0.41$ and the RMSE $=49 \mathrm{~W} \mathrm{~m}^{-2}$. To test the significance of this low correlation, a paired Student's $t$ test has been carried out. Although the test revealed that the result differs significantly from $R=0$ (probability $P=0.43$ ), this comparison does not provide sufficient information to determine on which days the difference in measured sensible heat fluxes is caused by heterogeneity within the experimental site, and on which days it is caused by other factors.

Considering the poor correlation shown in Fig. 7, an effort is made to better understand the influence of differences in characteristics of the footprints of LAS and $\mathrm{EC}$ on $\Delta H_{\text {Measured. }}$ Because of the relative slow evolution of the spatial variability in soil humidity, it can be assumed that the spatial variability in surface temperatures, as given by the satellite images, will remain constant during the day on which the image was acquired. It should be noted, however, that because of the shading of the soil by the canopy, the spatial variability of soil humidity will be most clearly seen after the sun has reached its zenith. In our case, all satellite overpasses took place in the morning ( $\sim 1050$ UTC for $\mathrm{ETM}+, \sim 1125 \mathrm{UTC}$ for ASTER). So, a relatively large part of the soil will be shaded from the sun by the olive tree crowns. Because of this effect, energy available for soil evaporation is limited, and consequently temperature differences between dry and wet soil are reduced. Besides this, part of the sunlit soil will be masked from the satellite by the canopy.

For seven half-hourly intervals (1100-1400 UTC) following the time of acquisition of each satellite image, the footprint-weighted surface temperatures have been calculated. Since Eq. (16) becomes a linear function of $T_{r}$ with $m=1$, we can use the differences between the LAS and EC footprint-weighted surface temperatures $\left(\Delta T_{r, \text { FOOTPRINT }}=\left\langle T_{r, \mathrm{LAS}}\right\rangle-\left\langle T_{r, \mathrm{EC}}\right\rangle\right)$ directly to study its influence on the difference between $H_{\text {LAS }}$ and $H_{\mathrm{EC}}$. These intervals were chosen since, even though they correspond to the top of the flux-time curve (resulting in limited correlation), the high solar angles will increase the effect of different footprint characteristics on the measured fluxes. It is found that when $\left|\Delta T_{r \text {,FOOTPRINT }}\right|$ is higher than approximately 0.5 $\mathrm{K}$, the large $\Delta H_{\text {Measured }}$ appears to be the result of the different characteristics of the footprints of the LAS and the EC system. The days for which this is the case correspond to days during which irrigation was either taking place, or had taken place shortly before (DOYs $311,359,90,138$, and 282; see the timeline of irrigation events and dates of satellite image acquisition shown in

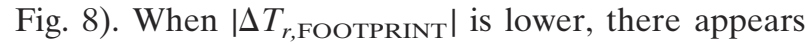
to be no correlation with the difference in sensible heat flux. For most of these intervals, the values found for $\Delta H_{\text {Measured }}$ are typical for a comparison between $H_{\mathrm{LAS}}$ and $H_{\mathrm{EC}}$ under homogeneous conditions (approximately $\pm 50 \mathrm{~W} \mathrm{~m}^{-2}$ ). For the remaining intervals $\left(\left|\Delta T_{r \text {,FOOTPRINT }}\right|<0.5 \mathrm{~K}\right.$, but $\Delta H_{\text {Measured }}$ relatively large), the reason for the relatively high value of $\Delta H_{\text {Measured }}$ can be explained by other factors, for example, irrigation taking place at the location of the EC system when the satellite image was acquired (DOY 42), or advection (DOY 58). Figure 9 shows $\Delta H_{\text {Measured }}$ plotted against $\left|\Delta T_{r \text {,FOOTPRINT }}\right|$ for the intervals when $\left|\Delta T_{r, \text { FOOTPRINT }}\right|>0.5 \mathrm{~K}$. For these intervals, $R^{2}=0.79$.

It should be noted that an uncertainty is introduced by the use of thermal infrared satellite images with spatial resolutions of 60 and $90 \mathrm{~m}$ for, respectively, the ETM+ and ASTER images. Figures 10a and 10b show 


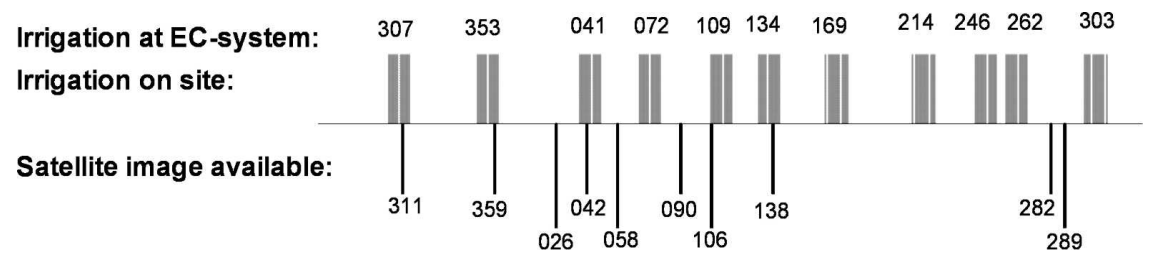

FIG. 8. Timeline showing the days on which satellite images are available and the 12-day periods during which irrigation events have taken place. Also indicated are the days on which irrigation reached the location of the EC system.

a superposition of the pixel grids of the ETM+ and ASTER images, respectively, as well as the footprints of the LAS and the EC system on the Quickbird image of the experimental site. Whereas the footprint of the LAS covers multiple pixels, the most important contribution to the EC flux often comes from within one pixel. Furthermore, as mentioned in section $2 b$, there are uncertainties associated with the use of footprint models. However, the spatial scales of the heterogeneities induced by irrigation (i.e., the irrigation sectors shown in Fig. 4) are large, both compared to the resolution of the satellite images, and compared to the size of the footprints. Therefore, the thermal infrared satellite images in combination with the footprint model are believed to provide realistic footprint-weighted radiative surface temperatures, and give a good indication of the degree of heterogeneity within the experimental area.

\section{Conclusions}

In this study, it is shown that both eddy covariance and scintillometer measurements provide reliable sen-

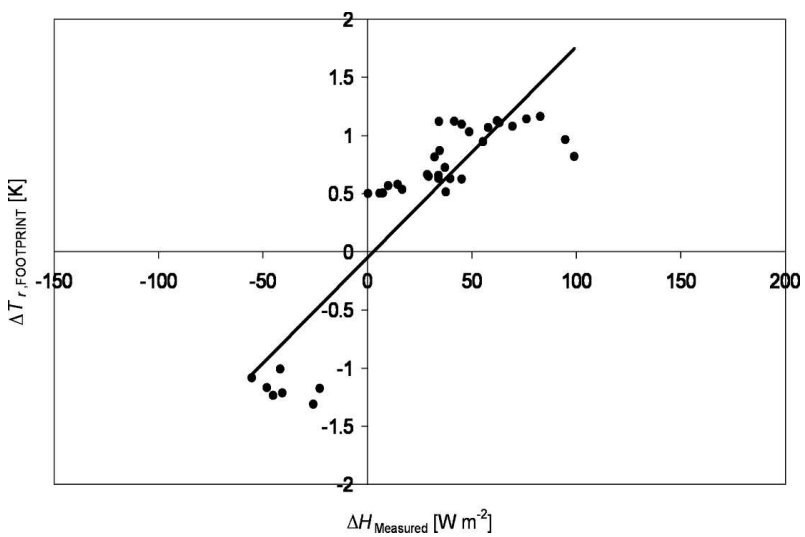

FIG. 9. Comparison of the difference in sensible heat flux measured by the LAS and the EC system $\left(\Delta H_{\text {Measured }}=H_{\text {LAS }}-\right.$ $\left.H_{\mathrm{EC}}\right)$ and the difference between the satellite-derived footprint-weighted radiative surface temperatures $\left(\Delta T_{r, \text { FOOTPRINT }}=\right.$ $\left.T_{r, \mathrm{LAS}}-T_{r, \mathrm{EC}}\right)$ for intervals with large spatial variability in soil humidity. sible heat flux estimates over an irrigated olive yard. When advection effects are minimal, MOST appears to hold well over tall, sparse vegetation. The sensible heat fluxes, measured by EC and LAS show a good correlation, provided that the source areas are homogeneous. There is a slight overestimation of sensible heat fluxes from the LAS, caused by the advection of dry air from the dry region surrounding the orchard. However, when the experimental area becomes heterogeneous, for example, due to irrigation, scatter becomes much larger and correlation worsens. In the present study, the heterogeneity within the experimental area is caused by differences in soil moisture due to the method of irrigation. Irrigation is applied in such a manner that for prevailing wind directions, the source area of the eddy covariance system is irrigated well before the source area of the scintillometer. This causes the two source areas to be no longer comparable in soil humidity and, thus, surface temperature.

To quantify the difference between sensible heat flux obtained from the LAS and the EC system, the formulation of the sensible heat flux as found by Lhomme et al. (1994) is used. This method is tested against the eddy covariance measurements using in situ measurements of radiative surface temperature, and it is shown that the fluxes calculated using this model depend linearly on the radiative surface temperature. This enables the direct use of Landsat-7 ETM+ and ASTER-derived radiative surface temperatures, weighted using the footprint functions of LAS and EC, in an effort to account for differences between sensible heat fluxes, measured by EC and LAS, caused by heterogeneities within the source areas of the EC system and the LAS. The satellite-derived surface temperature is used as an indication of the spatial variability of soil humidity, and it is assumed that the change in soil moisture distribution throughout the orchard is minimal during the hours following the time of satellite overpass. Footprints of both LAS and EC have been computed for seven 30-min intervals following the time of acquisition of the image, and using the satellite image, the footprint-weighted radiative surface temperatures for each 
(a)

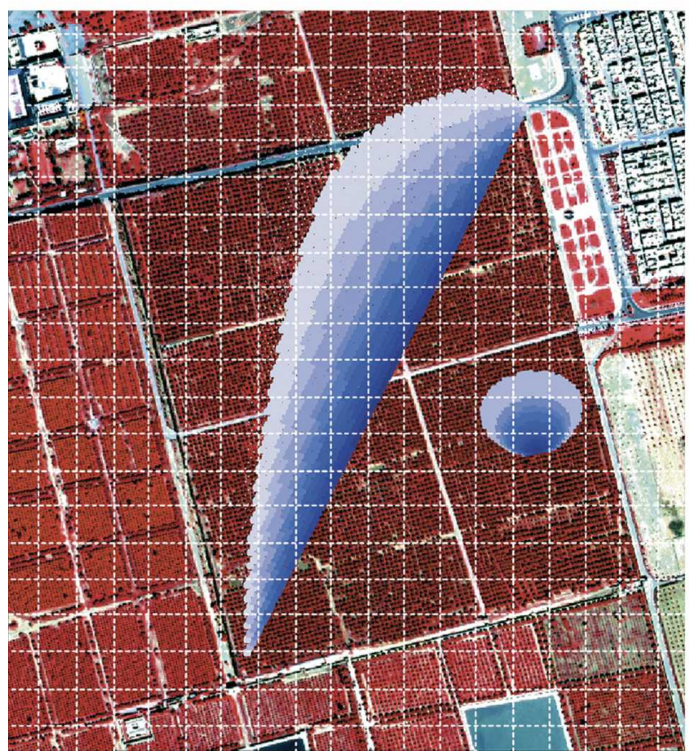

(b)

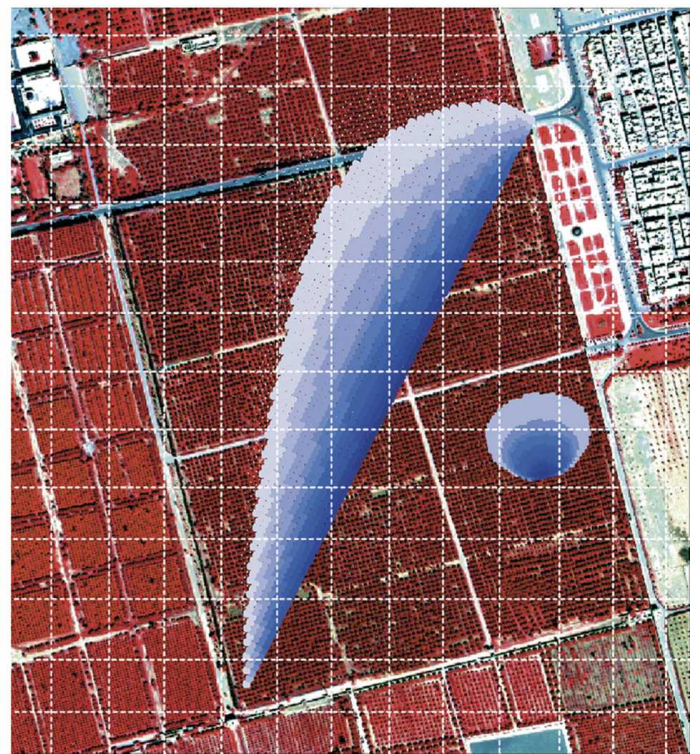

FIG. 10. Quickbird satellite image with the (a) ETM+ and (b) ASTER pixel grids (60- and 90-m resolution, respectively) and LAS and EC footprints superposed.

interval are calculated. Comparing the differences between these radiative surface temperatures against the differences in measured flux for each interval shows that when the difference in footprint-weighted radiative surface temperature exceeds approximately $\pm 0.5 \mathrm{~K}$, correlation is good. When the difference in footprint weighted radiative surface temperature is less than $\pm 0.5 \mathrm{~K}$, there is no correlation between the two, and any disagreement between $H_{\mathrm{LAS}}$ and $H_{\mathrm{EC}}$ is likely to be caused by other factors.

Considering the assumptions that are made, the result is very promising. For a site where heterogeneity is mainly caused by differences in soil humidity, a large part of the difference between the sensible heat fluxes obtained from LAS and EC can be explained using thermal infrared satellite imagery as the result of differences in the characteristics of the footprints of each method. The result of this study shows the importance of assessing differences between footprint characteristics when comparing different methods for the estimation of surface fluxes or when using flux measurements for the validation of models.

Acknowledgments. Research cited in this paper benefited from support of the INCO-MED program of the European Commission (DG Research, 5th FWP) through the IRRIMED project. We are grateful to the director and staff of the Agdal olive orchard for allowing us access to and use of the field site. We thank O. K. Hartogensis for the organization of, and his assistance in carrying out, the Wageningen University contribution to the IRRIMED experiment in Agdal. A. van den Kroonenberg and D. van den Bersselaar are acknowledged for their assistance during the first part of the experiment. V. Simonneaux is thanked for his assistance on remote sensing issues, and G. Boulet is thanked for his assistance during the experiment. During the first part of the experiment, J. C. B. Hoedjes was supported by a fellowship from STW, Netherlands (Project WMO4133).

\section{REFERENCES}

Andreas, E. L, and B. B. Hicks, 2002: Comments on "Critical test of the validity of Monin-Obukhov similarity during convective conditions." J. Atmos. Sci., 59, 2605-2607.

Baldocchi, D., 1997: Flux footprints within and over forest canopies. Bound.-Layer Meteor., 85, 273-292.

Bernhofer, C., and R. Vogt, 1999: Energy balance closure gaps-A methodological problem of eddy covariance measurements? Proc. Int. Congress of Biometeorology, Sydney, Australia, International Society of Biometeorology, CDROM, 270

Bosveld, F. C., A. A. M. Holtslag, and B. J. J. M. Van den Hurk, 1999: Interpretation of crown radiation temperatures of a dense Douglas fir forest with similarity theory. Bound.-Layer Meteor., 92, 429-451.

Brutsaert, W., 1982: Evaporation into the Atmosphere. Reidel, 299 pp.

Chehbouni, A., and Coauthors, 1999: Estimation of area-average sensible heat flux using a large-aperture scintillometer during the Semi-Arid Land-Surface-Atmosphere (SALSA) experiment. Water Resour. Res., 35, 2505-2511. 
- , and Coauthors, 2000: Estimation of heat and momentum fluxes over complex terrain using a large aperture scintillometer. Agric. For. Meteor., 105, 215-226.

Choudhury, B. J., and J. L. Monteith, 1988: A four-layer model for the heat budget of homogeneous land surfaces. Quart. J. Roy. Meteor. Soc., 114, 373-398.

De Bruin, H. A. R., N. J. Bink, and L. J. M. Kroon, 1991: Fluxes in the surface under advective conditions. Land Surface Evaporation: Measurement and Parameterization, T. J. Schmugge and J. C. André, Eds., Springer-Verlag, 157-169.

_- W. Kohsiek, and B. J. J. M. Van den Hurk, 1993: A verification of some methods to determine the fluxes of momentum, sensible heat, and water vapour using standard deviation and structure parameter of scalar meteorological quantities. Bound.-Layer Meteor., 63, 231-257.

- B. J. J. M. Van den Hurk, and W. Kohsiek, 1995: The scintillation method tested over a dry vineyard area. Bound.Layer Meteor., 76, 25-40.

— - W. M. L. Meijninger, A.-S. Smedman, and M. Magnusson, 2002: Displaced-beam small aperture scintillometer test. Part I: The WINTEX data-set. Bound.-Layer Meteor., 105, 129148.

—, O. K. Hartogensis, R. G. Allen, and J. W. J. L. Kramer, 2005: Regional advection perturbations in an irrigated desert (RAPID) experiment. Theor. Appl. Climatol., 80, 143-152.

Finn, D., B. Lamb, M. Y. Leclerc, and T. W. Horst, 1996: Experimental evaluation of analytical and Lagrangian surface-layer footprint models. Bound.-Layer Meteor., 80, 283-308.

Green, A. E., K. J. McAneney, and M. S. Astill, 1994: Surface layer scintillation measurements of daytime sensible heat and momentum fluxes. Bound.-Layer Meteor., 68, 357-373.

—, M. S. Astill, K. J. McAneney, and J. P. Nieveen, 2001: Pathaveraged surface fluxes determined from infrared and microwave scintillometers. Agric. For. Meteor., 109, 233-247.

Gryning, S. E., E. Batchvarova, and H. A. R. De Bruin, 2001: Energy balance of a sparse coniferous high-latitude forest under winter conditions. Bound.-Layer Meteor., 99, 465-488.

Hartogensis, O. K., and H. A. R. De Bruin, 2005: MoninObukhov similarity functions of the structure parameter of temperature and turbulent kinetic energy dissipation rate in the stable boundary layer. Bound.-Layer Meteor., 116, 253 276.

, - — , and B. J. H. Van de Wiel, 2002: Displaced-beam small aperture scintillometer test. Part II: CASES-99 stable boundary layer experiment. Bound.-Layer Meteor., 105, 148-176.

_ C. C. Watts, J.-C. Rodriguez, and H. A. R. De Bruin, 2003: Derivation of an effective height for scintillometers: La Poza experiment in northwest Mexico. J. Hydrometeor., 4, 915928.

Hicks, B. B., 1981: An examination of turbulence statistics in the surface boundary layer. Bound.-Layer Meteor., 21, 389-402.

Hill, R. J., 1997: Algorithms for obtaining atmospheric surfacelayer fluxes from scintillation measurements. J. Atmos. Oceanic Technol., 14, 456-467.

Hoedjes, J. C. B., R. M. Zuurbier, and C. J. Watts, 2002: Large aperture scintillometer used over a homogeneous irrigated area, partly affected by regional advection. Bound.-Layer Meteor., 105, 99-117.

Horst, T. W., 1999: On frequency response corrections for eddy covariance flux measurements. Bound.-Layer Meteor., 94, 517-520.

, and J. C. Weil, 1992: Footprint estimation for scalar flux measurements in the atmospheric surface layer. Bound.Layer Meteor., 59, 279-296.

— ments for micrometeorological measurement of surface fluxes. J. Atmos. Oceanic Technol., 11, 1018-1025.

Johansson, C., A.-S. Smedman, U. Högström, J. G. Brasseur, and S. Khanna, 2001: Critical test of the validity of MoninObukhov similarity during convective conditions. J. Atmos. Sci., 58, 1549-1566.

,,,--- and,- 2002 : Reply. J. Atmos. Sci., 59, 26082614.

Klipp, C. L., and L. Mahrt, 2004: Flux-gradient relationships, selfcorrelation and intermittency in the stable boundary layer. Quart. J. Roy. Meteor. Soc., 130, 2087-2103.

Lagouarde, J.-P., F. Jacob, X.-F. Gu, A. Olioso, J.-M. Bonnefond, Y. H. Kerr, K. J. McAneney, and M. Irvine, 2002: Spatialization of sensible heat flux over a heterogeneous landscape. Agronomie, 22, 627-633.

Leclerc, M. Y., S. Shen, and B. Lamb, 1997: Observations and large-eddy simulation modeling of footprints in the lower convective boundary layer. J. Geophys. Res., 102, 9323-9334.

Lhomme, J.-P., B. Monteny, and M. Amadou, 1994: Estimating sensible heat flux from radiometric temperature over sparse millet. Agric. For. Meteor., 68, 77-91.

Massman, W., and R. Clement, 2004: Uncertainty in eddy covariance flux estimates resulting from spectral attenuation. Handbook of Micrometeorology-A Guide for Surface Flux Measurement and Analysis, X. Lee, W. Massman, and B. Law, Eds., Kluwer Academic, 67-99.

McAneney, K. J., A. E. Green, and M. S. Astill, 1995: Large aperture scintillometry: The homogeneous case. Agric. For. Meteor., 76, 149-162.

Meijninger, W. M. L., 2003: Surface fluxes over natural landscapes using scintillometry. Ph.D. thesis, Wageningen University and Research Centre, 164 pp.

_ , and H. A. R. De Bruin, 2000: The sensible heat fluxes over irrigated areas in western Turkey determined with a large aperture scintillometer. J. Hydrol., 229, 42-49.

—_, A. E. Green, O. K. Hartogensis, W. Kohsiek, J. C. B. Hoedjes, R. M. Zuurbier, and H. A. R. De Bruin, 2002a: Determination of area-averaged water vapour fluxes with large aperture and radio wave scintillometers over a heterogeneous surface. Bound.-Layer Meteor., 105, 63-83.

- O. K. Hartogensis, W. Kohsiek, J. C. B. Hoedjes, R. M. Zuurbier, and H. A. R. De Bruin, 2002b: Determination of area-averaged sensible heat fluxes with a large aperture scintillometer over a heterogeneous surface-Flevoland field experiment. Bound.-Layer Meteor., 105, 37-62.

Merlin, O., A. G. Chehbouni, Y. H. Kerr, E. G. Njoku, and D. Entekhabi, 2005: A combined modeling and multi-spectral/ multi-resolution remote sensing approach for disaggregation of surface soil moisture: Application to SMOS configuration. IEEE Trans. Geosci. Remote Sens., 43, 2036-2050.

Moene, A. F., 2003: Effects of water vapour on the structure parameter of the refractive index for near-infrared radiation. Bound.-Layer Meteor., 107, 635-653.

Moncrieff, J. B., and Coauthors, 1997: A system to measure surface fluxes of momentum, sensible heat, water vapour and carbon dioxide. J. Hydrol., 188-189, 589-611.

Moore, C. J., 1986: Frequency response corrections for eddy correlation systems. Bound.-Layer Meteor., 37, 17-35.

Oncley, S. P., and Coauthors, 2002: The energy balance experiment EBEX-2000. Preprints, 15th Conf. on Boundary Layer 
and Turbulence, Wageningen, Netherlands, Amer. Meteor. Soc., $1-4$.

Panofsky, H. A., and J. A. Dutton, 1984: Atmospheric Turbulence: Models and Methods for Engineering Applications. Wiley, 397 pp.

Rannik, Ü., M. Aubinet, O. Kurbanmuradov, K. K. Sabelfeld, T. Markkanen, and T. Vesala, 2000: Footprint analysis for measurements over a heterogeneous forest. Bound.-Layer Meteor., 97, 137-166.

Schotanus, P., F. Nieuwstadt, and H. A. R. De Bruin, 1983: Temperature measurement with a sonic anemometer and its application to heat and moisture fluxes. Bound.-Layer Meteor., 26, 81-93.

Schuepp, P. H., M. Y. Leclerc, J. I. MacPherson, and R. L. Desjardins, 1990: Footprint prediction of scalar fluxes from analytical solutions of the diffusion equation. Bound.-Layer Meteor., 50, 355-373.

Shuttleworth, W. J., and R. J. Gurney, 1990: The theoretical relationship between foliage temperature and canopy resistance in sparse crops. Quart. J. Roy. Meteor. Soc., 116, 497-519.

Stull, R. B., 1988: An Introduction to Boundary Layer Meteorology. Kluwer Academic, 670 pp.

Twine, T. E., and Coauthors, 2000: Correcting eddy-covariance flux underestimates over a grassland. Agric. For. Meteor., 103, 279-300.

Van Dijk, A., W. Kohsiek, and H. A. R. De Bruin, 2003: Oxygen sensitivity of krypton and lymann- $\alpha$ hygrometers. J. Atmos. Oceanic Technol., 20, 143-151.

, A. F. Moene, and H. A. R. De Bruin, 2004: The principles of surface flux physics: Theory, practice and description of the ECPACK library. Internal Rep. 2004/1, Meteorology and Air Quality Group, Wageningen University, Wageningen, Netherlands, 99 pp.

Vogt, R., A. Christen, and A. Pitacco, 2004: Scintillometer measurements inside two tree canopies. Preprints, 26th Conf. on Agricultural and Forest Meteorology, Vancouver, BC, Canada, Amer. Meteor. Soc., CD-ROM, P1.26.

Wallace, J. S., 1995: Calculating evaporation: Resistance to factors. Agric. For. Meteor., 73, 353-366.

Wang, T., G. R. Ochs, and S. F. Clifford, 1978: A saturation resistant optical scintillometer to measure . J. Opt. Soc. Amer., 68, 334-338.

Watts, C. J., A. Chehbouni, J.-C. Rodriguez, Y. H. Kerr, O. K. Hartogensis, and H. A. R. De Bruin, 2000: Comparison of sensible heat flux estimates using AVHRR with scintillometer measurements over semi-arid grassland in northwest Mexico. Agric. For. Meteor., 105, 81-89.

Webb, E. K., G. I. Pearman, and R. Leuning, 1980: Correction of flux measurements for density effects due to heat and water vapour transfer. Quart. J. Roy. Meteor. Soc., 106, 85-100.

Wesely, M. L., 1976: The combined effect of temperature and humidity fluctuations on refractive index. J. Appl. Meteor., 15, 43-49.

Wilczak, J., S. Oncley, and S. A. Stage, 2001: Sonic anemometer tilt correction algorithms. Bound.-Layer Meteor., 99, 127-150.

Williams, D. G., and Coauthors, 2004: Evapotranspiration components determined by stable isotope, sap flow and eddy covariance techniques. Agric. For. Meteor., 125, 241-258. 